\title{
Japanese stone monuments and disaster memory - perspectives for DRR
}

\author{
Emmanuel Garnier \\ CNRS Chrono-Environnement Laboratory, CNRS, Besonçon, France, and \\ Florence Lahournat \\ Disaster Prevention Research Institute, Kyoto University, Kyoto, Japan
}

Disaster memory

\begin{abstract}
Purpose - The paper focuses on an aspect of disaster often overlooked by experts: that of disaster memory both as a prevention tool and one potentially contributing to the resilience of vulnerable communities in Japan. The objective is, more specifically, to explore one specific source of disaster memory in Japan, namely the disaster-related stone monuments scattered throughout the archipelago.

Design/methodology/approach - To achieve the goals, the authors have studied several types of materials. First, the authors have used the "Natural Disaster Monument" online database compiled by the Geospatial Information Authority of Japan (GIS), data upon which the authors based the field research study, focused on water-related disaster in Otsu city (Shiga Prefecture). Simultaneously, the authors have systematically searched Japanese newspapers since the middle of the 19th century as well as the archives of Shiga prefecture in order to collect additional information on the statistical reality of these monuments, the context of their creation and in order to better estimate the severity of our case studies.

Findings - First, the findings show that stone monuments are indeed structuring elements of disaster memory in Japan. Not only are they present throughout the archipelago, but in addition, they are still for the most part visited by local communities. Second, the findings show how this material culture of disaster, as a vector of disaster memory, could be used as a tool to better understand and bring awareness to the occurrence of specific hazards, especially to future generations.

Originality/value - The authors promote an interdisciplinary approach by associating anthropology and history. The study offers a new and original character about an object of study relating to both the cultural and historical fields but still often neglected as a tool and object of research in DDR. The authors provide a method and suggest ways to integrate these stone monuments into DDR policies. Finally, the authors propose to better integrate these monuments into the overall reflection on disaster awareness and disaster mitigation.
\end{abstract}

Keywords Stone monument, Disaster, Japan, Interdisciplinarity, Material culture

Paper type Research paper

(C) Emmanuel Garnier and Florence Lahournat. Published by Emerald Publishing Limited. This article is published under the Creative Commons Attribution (CC BY 4.0) licence. Anyone may reproduce, distribute, translate and create derivative works of this article (for both commercial and non-commercial purposes), subject to full attribution to the original publication and authors. The full terms of this licence may be seen at http://creativecommons.org/licences/by/4.0/legalcode

The authors would like to thank the GeoSpatial Information Authority of Japan (GSI) and the Lake Biwa Museum, more specifically Dr. Robin J. Smith and Michinori Hashimoto for the constant help and expertise. Emmanuel Garnier also wishes to thank the Disaster Prevention Research Institute (Cruz Laboratory) at Kyoto University, which hosted him as a visiting professor, the Bourgogne Franche-Comté Region and the CNRS PICSSECURES for funding this project and the Japan Times Newspaper for making old copies available on its online site. Florence Lahournat wishes to acknowledge that this work was supported by JSPS KAKENHI [Grant No. 20K01215].

The authors are indebted to Dr Nick Marriner (UMR CNRS ThéMA, the University of Franche-Comté) for the kind revision of text.
Received 19 March 2021

Revised 16 July 2021

10 October 2021

16 October 2021

Accepted 16 October 2021 
DPM

31,6

2

\section{Introduction}

Japan is vulnerable to a variety of hazards, including earthquakes, tsunamis, typhoons and volcanic eruptions. Almost $20 \%$ of the world's large-scale earthquakes (magnitude 6 and above) occur in Japan. Although Japan constitutes just $0.28 \%$ of the Earth's land area and only $1.9 \%$ of the world's population, the country is the site of $18.5 \%$ of earthquakes of magnitude 6 or greater and $7 \%$ of active volcanoes.

Only 1.5\% of the victims of disasters in the world are residents of Japan, but $17.5 \%$ of their financial damages are in the country. Japan has made progress in building embankments and other disaster prevention measures, which have limited the forms of damage once caused by typhoons and calamities, which sometimes claimed more than 1,000 lives at a time. Nonetheless, severe disaster events, notably earthquakes and torrential rains, continue to cause major damage, including, in recent years, the 2011 Great East Japan Earthquake, which left approximately 20,000 dead and missing, and the 2020 Kyushu floods, which left 85 dead and missing and damaged more than 15,300 buildings.

Based on these observations and the limitations of mitigation measures heavily, if not exclusively, reliant on engineering-based solutions, the objective of this study is to focus on the merits of an interdisciplinary approach, specifically one that embraces the importance the memory of past disasters and more generally to cultural memory.

Indeed, remembering past disasters offers significant value at the community level (Garnier, 2019). Memories of previous disasters not only inform people's knowledge of their environment and vulnerability but it also influences their interpretation of risk and their response to future disasters. The memory of disaster may be conveyed in public life through different means, ranging from tangible expressions, like memorial plaques, to intangible records, such as myths. Over time, these manifestations of disaster memory provide communities with knowledge, practices and techniques that contribute to a better adaptation to their specific environment and can help make sense of the events, once in the recovery phase. Memories play an important role in determining the way people respond to disaster risk, engage in disaster management practices and accept disaster relief in an emergency situation. It is therefore crucial that response agencies become aware of and accept the different logics and rationalities that people rely on when faced with disaster. A valuable concept in this regard is "cultural memory". Cultural memory ensures that meanings and interpretations of disasters are recorded and handed down from generation to generation. It provides a means by which a population can understand, contextualize, prepare for and recover from hazards and disasters (Mendonça and Amorin, 2018). On the one hand, collective memory is based on oral tradition shared by a specific group, most commonly the family, and tends to disappear with the death of the last eyewitness to the event. Cultural memory, on the other hand, goes further back and is understood as long-term social memory based partly on written and material sources. Moreover, cultural memory has to be supported by documents, such as newspapers, archives, images and monuments.

This paper presents preliminary steps in exploring disaster-related stone monuments as a tool for better understanding the transmission of disaster memory. In order to do so, this study considers instances of commemorative stones found in Japan. These stone monuments, as elements of both material and immaterial culture, show the existence of a memorialization of disaster and supposedly reflect the will to commemorate and transmit significant past events to current and future generations, having a potential role to play in a more informal risk mitigation system.

\section{Relevance of a research devoted to disaster-related memory stones}

This project focuses on disaster memory as a prevention tool as well as a potential vector of resilience to help reduce the vulnerability of local communities. 
Focusing on disaster memory and its material vectors in the context of disaster risk reduction (DRR) could be perceived as a departure from other more modern and more technical approaches, but constitutes, nonetheless, key steps in the development of more integrated approaches to DRR.

The prevalence of these stone monuments in Japan is a surprising phenomenon to the outsider's eye. Indeed, such a visual legacy of past disasters integrated into today's landscapes is probably unique on a global scale, in terms of quantity, architectural forms and geographic distribution. In the West, especially in Europe, the material vectors of disaster memory are less common and do not seem to offer comparable physical homogeneity. Within Christian cultures, the most common markers are the ex-votos; these small naive paintings depicting disasters were hung in Catholic churches in order to perpetuate the memory of these destructive events within the parish. While the location of these pictorial testimonies in churches was relevant in the past, it no longer is today, due to the dechristianization of Western countries and the collapse of religious practice. Even less common, calvaries and crosses were sometimes erected to honor the victims of a disaster in a place of passage, such as a mountain pass, a slope exposed to avalanches or a road junction. From the 17th century onwards, the rise of science saw the emergence of disaster related secular monuments, such as commemorative plaques and markers of floods and storm surges. Since the Second World War, these landmarks have often been destroyed by urbanization, the development of industrial and communications infrastructures (roads, railways and canals) as well as population migrations. In this last instance, newcomers from other regions have often replaced the original residents. Under these circumstances, newcomers and their elected officials have often deemed the preservation of these monuments unnecessary because they no longer know their meaning (Garnier, 2019). These geographic mobilities explain, for instance, the feeling of novelty and unpredictability that prevails on European coasts in the face of storm surges (Garnier et al., 2017).

In contrast, because of their prevalence and geographical distribution, disaster-related stone monuments in Japan are symbols of a risk culture deeply rooted in the memory of people across the archipelago. More importantly, many of these stone monuments are still visible, known and interacted with, for reasons specific to the Japanese cultural and social contexts, such as, for example, Buddhist practices linked to death, the maintenance of local communities on site and tourist attraction for these places of memory. Whereas other cultures have produced monuments to commemorate disasters and their victims, Japan may well be a unique example in terms of geographic density and pervasiveness, as well as descriptive content of historical disasters.

While the 2011 Great Japan Earthquake and Tsunami (CEJET) has generated a renewed interest in tsunami related stones specifically, historians and anthropologists have shown comparatively little interest in this type of material. Initiatives to raise public awareness to these testimonies of past disasters were carried out in the early 2000 s by historians, but were generally limited to one-off exhibitions briefly evoking these stone monuments. These projects did not provide any real focus on integrating this heritage into a more global reflection on preparedness and prevention strategies (Kitahara, 2004). There is still a paucity of research looking at their history, their sociocultural significance and the reasons why they remain quite common in a country that has undergone significant economic and social changes in recent decades.

As mentioned previously, the 2011 GEJET shed a new light on the Tōhoku tsunami memory stones, exposing them beyond the boundaries of local communities. This is notably the case of the now world-famous Aneyoshi tsunami stone in Iwate Prefecture (New York Times, April 20, 2011. https://www.nytimes.com/2011/04/21/world/asia/21stones.html). Western journalists who came to report on the aftermath of the 2011 GEJET learned of these stones from survivors and mentioned them in their articles during the following months 
DPM

31,6

4

and years. By contrast, few scientists and experts have integrated this heritage into their studies, however plethoric, nor in their risk reduction policies. This is probably because these studies have been overwhelmingly carried out by specialists in the applied physical sciences (geologists, seismologists and engineers). One notable exception is found in the work of Suppasri et al. (2013) looking at lessons learned from the 2011 GEJET, where they underline the role of tsunami memorial stones in the transmission of disaster memory and, as such, as "symbols of tsunami prevention". The authors drew a link between datable sedimentary deposits and historical disasters marked by tsunami memorial stones. They recommended using them as complementary tools for tsunami awareness and disaster mitigation and more specifically to map at risk areas in the municipalities of Tohoku.

\subsection{Distribution and chronology of disaster-related memory stones in Japan}

Taking into account the relative absence of interdisciplinary scientific research looking at disaster-related stone monuments, the present study uses the "Natural Disaster Monument" online database of the Geospatial Information Authority of Japan (GSI), accessible on the "GSI maps" Website (https://www.gsi.go.jp/bousaichiri/denshouhi.html). This long-term project calls on the goodwill of the Japanese municipalities and prefectures to provide information on their local disaster-related monuments. One of the objectives of the database is to provide Japanese citizens with a better understanding of the reality of natural hazards and to strengthen their disaster preparedness. The GSI began collecting information on this type of monuments in the spring of 2019, in cooperation with local governments, the Regional Development Bureau of MLIT (Ministry of Land, Infrastructure, Transport and Tourism) and by soliciting around 200 municipalities. As a result, the database is not exhaustive, with currently more than 300 stone monuments listed, but a work in progress, with new information being continuously added by local stakeholders.

Keeping in mind the nonexhaustive nature of the GSI database, it is still possible to draw a few observations. The mapping of the disaster-related memory stones identified by the GSI survey reveals a clear dual territorial opposition (Figure 1). The first opposes the coastal regions to the interior regions with more than $80 \%$ of the recorded memory stones located on the coasts, with strong concentrations in Tōhoku (northeastern region of the Honshu island), Kanto (Tokyo region), the regions of Nagoya and Kobe (south of the Honshu island) and finally the western part of the Kyushu island. In the specific case of Tohoku, memory stones are much more frequent near the towns of Aomori, Iwate, Miyagi and Sendai, all severely hit by the 2011 GEJET. By contrast, the GSI survey only records two memory stones in and around Fukushima.

The second clear opposition on the GSI map contrasts the Pacific seaboard and the Sea of Japan coastline. In fact, the western part of the country hosts just over $10 \%$ of the memory stones in the GSI database, with the highest concentrations in West Tōhoku and in the prefectures of Niigata and Yamaguchi.

Figure 2 shows the number of memory stones by disaster type. It should be noted that these only reflect disasters that local residents and governments felt were necessary to remember. For this reason, these data have no statistical significance in terms of frequency and intensity of disasters. Moreover, one single stone can refer to cascading disasters such as, for example, an earthquake which successively triggers a landslide and/or a tsunami.

First in this list of memorable events is tsunami, comprising $42 \%$ of all marked disasters. The overrepresentation of this type of disaster therefore explains their concentration on Japanese coasts (mainly the Pacific coast), particularly exposed to tsunami. Then follow earthquakes $(26 \%)$, floods $(12 \%)$ and typhoons $(7 \%)$. The category of "heavy rain" $(5 \%)$ is challenging because heavy rains are strongly linked to the following disasters: mudflows, landslides, volcanic eruptions and storm surges; these four types of disasters together 


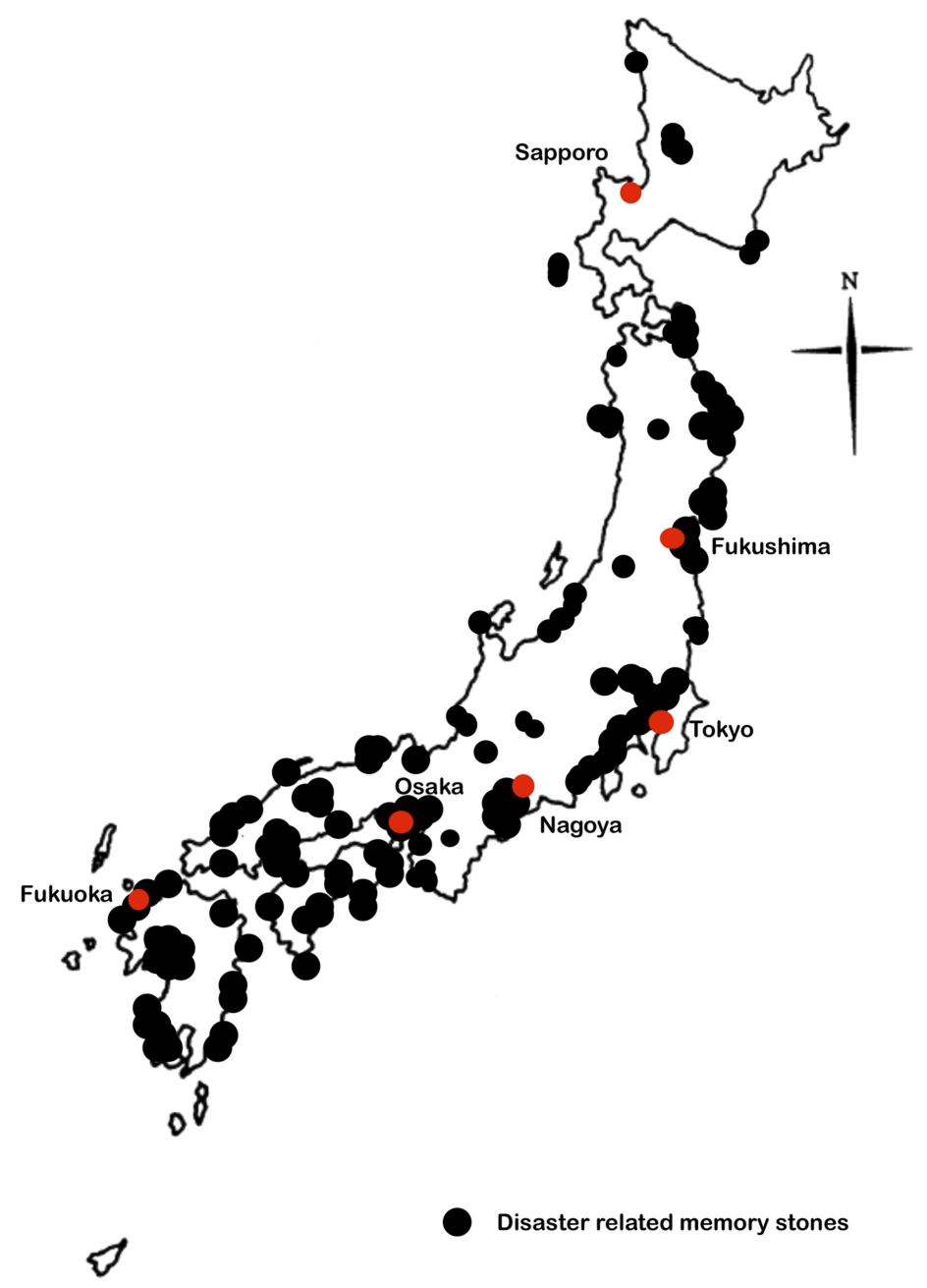

Disaster memory

Figure 1. Geographic distribution of disasterrelated memory stones in Japan

account for just $8 \%$ of the total. This typology is surprising when compared with the most recent studies and government surveys, which identify typhoons and heavy rains as the main causes of disaster-related deaths.

More unexpected is the chronology of the erection of these monuments. As seen in Figure 3, these monuments are relatively recent, with most of them dating back to the second half of the 19 th century. Only 10\% date to before 1850. It would therefore seem that the Meiji period (1868-1912), during which the Japanese government embarked on a policy of modernization en force of the country, has played an important role in the generalization of disaster-related memory stones. From a historical standpoint, this is a significant observation, as it shows that this modernization, which was carried out by resorting massively to Western engineering and techniques, was also associated with a desire to promote the memory of disasters, the peak of which occurs between 1900 and 1950. The number of monuments then declines, and their relatively large number since the 2000s can mostly be explained by the 2011 tsunami, which led to many new constructions. 


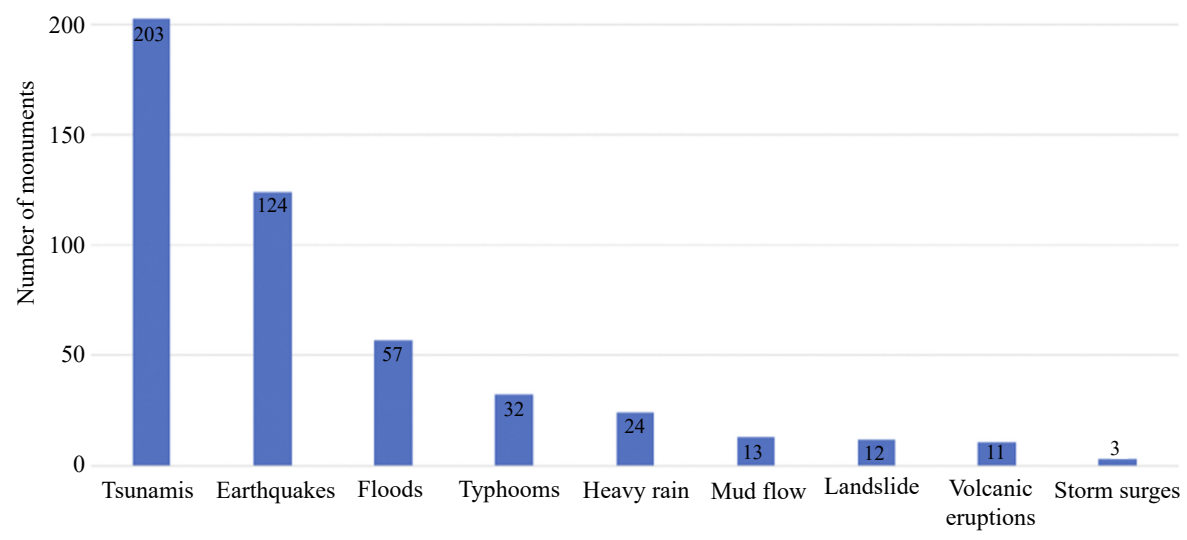

Figure 2.

Types of disasters at stone monuments

\section{Figure 3.}

Chronology (49-year periods) of Japanese disaster-related memory stones

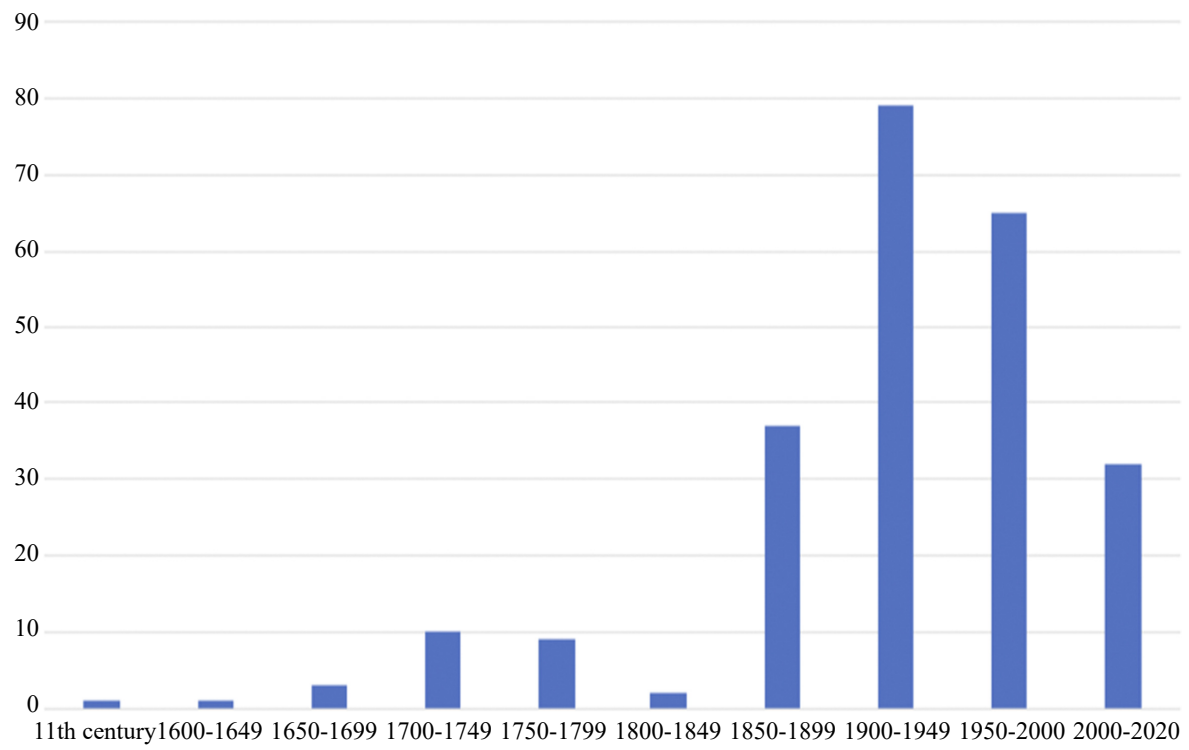

\subsection{Stone monuments according to Japanese newspapers}

In the absence of administrative documentation, consulting the archives of Japanese newspapers, such as the Mainichi Shimbun, the Tokyo Shimbun and The Japan Times, has shed interesting light on the context of the erection of these monuments. Let us consider both the timing of their construction and the actors involved.

At the end of the 19th century, a public debate arose regarding the erection of commemorative monuments in Japan. The press, along with government authorities, denounced the excessive use of this commemorative practice, which now concerns both disasters and local heroes and benefactors. It was thus recommended from this time on to 
publish the biographies of notable personalities and reserve the use of commemorative stone monuments for matters more important to the communities. This recommendation appears to have been acted upon, since the 22 examples of stone monuments erections reported by the above newspapers between 1900 and 1960 all commemorate a disaster. Their study shows that they were officially inaugurated within a period of between 1 and 6 years after the disaster and that their height varies between 1.50 and $2.70 \mathrm{~m}$. The oldest explain, in the form of a short text, that they were erected "to warn all future generations against the danger of living on the site" devastated by a disaster. These monuments can sometimes recall a very high mortality in a village or a city, sometimes focusing on the deaths of major social actors, such as teachers or scientists, who fell victims to the disaster whilst undertaking professional duties or who have demonstrated exemplary courage to save the lives of their students. Monuments are usually funded by collections from survivors and schoolchildren, often supplemented by public funding. For example, for the erection of the monument in memory of the 500 Tokyo primary school students killed during the 1923 Kanto earthquake, the educational authorities of the Tokyo city took the initiative to launch the collection among the students of the city in 1928. In terms of appearance, these monuments being mainly located within temple precincts, many take on a traditional Japanese style. Otherwise, they can be, as some press articles describe, "in the foreign style" (meaning Western), as was the case for a monument commemorating the death of teachers during the 1934 typhoon in Kyoto, representing two children and a teacher protecting them (The Japan Times, July 20, 1935) The inauguration ceremonies seem to commonly bring together officials (governor, representatives of ministries, mayor and elected municipal officials), local residents and give rise to a religious service.

\section{Disaster-related memory stones in context}

\subsection{A typology of Japanese disaster-related memory stones}

In order to give context to this discussion, we need to explore the positioning of disasterrelated memory stones as an element of Japanese specific disaster culture. As mentioned previously, it is important to note that stone monuments in Japan are not limited to disaster memorialization. They are in fact common across a variety of cultural domains, making them a familiar type of material culture in the Japanese context.

In their respective work on tsunami-related memory stones in the Tōhoku region, historian Kitahara (2001) and folklorist Kawashima (2016) suggest that these monuments can be classified in two distinct categories, based on their respective function: kinen-hi and $k u y \bar{o}-h i$. This typology remains relevant when considering memory stones related to other disasters as well, as seen throughout the GSI database.

In the context of disaster memorialization, kinen-hi or commemorative stones, essentially mark a specific event, whereas kuyo-hi, or memorial stones, are dedicated to the memory of those who have been lost. The former focuses on memorializing the disaster itself, while the latter focuses on the lost lives, and on offering a place of comfort for the souls of the deceased and for those who remain. In this regard, $k u y \bar{o}-h i$ can likely be interpreted as a variation of a collective grave or a cenotaph (Boret and Shibayama, 2018). These kuyô-hi tend to be associated with regular memorial rituals for the repose of the soul of the dead and are, as such, often associated with Buddhist practices.

\subsection{Historical development and evolution of disaster-related memory stones}

Within the wider category of disaster-related memory stones, tsunami-related stones (tsunami-hi) have generated the most research, possibly due to the destructive nature of these hazards. The National Museum of Ethnology has notably created a participative database of 
DPM

31,6

8

Cultural Heritage Sites Possessing Memories of Tsunamis: Database of Temples/Shrines and Stone Monuments that currently includes 279 monument-related entries (http://sekihi. minpaku.ac.jp/). Disaster-related memory stones carry a variety of messages: religious inscriptions (most often Buddhist sutras), accounts of the disaster pertaining to human loss, material destruction, characteristics of the hazard and instructions on adequate behavior (e.g. invective to "go to higher ground"). The extensive body of memory stones across Japan illustrates the will to transmit the memory of a significant event or loss. Furthermore, the variations in the content of the inscriptions on the stones provide insights into the changes in understanding and perception of hazards and disasters.

Older memory stones are largely associated with Buddhist beliefs, and, as such, mostly fall into the memorial stone category mentioned previously. The oldest known tsunami stone, Kōryaku-hi, erected in 1,380 in Yuki (now Minami town, Tokushima prefecture), is a representative example. Inscribed with a Buddhist sutra, it is dedicated to the victims of the 1,361 Nankai earthquake and tsunami. Later, from the 17th century onwards, syncretic forms of memory stones make their apparition, combining elements from both Buddhist and Shinto traditions (Murakami, 2008). While concrete descriptions of hazards appear sporadically on earlier stones (e.g. the Keichō and Hōei Earthquakes and Tsunamis stone in Kaiyō town, Tokushima prefecture), the Edo period (1,603-1868) sees an increase in this trend, potentially correlated with an increase in literacy (Deal, 2006 cited by Good, 2016). Memory stones henceforth commonly document the date, time and characteristics (e.g. water level) of the hazard.

While Buddhist beliefs had attributed the onset of disaster to karmic retribution and Shinto beliefs surrounding earthquakes revolved around the deity Kashima failing to control the giant catfish under the Earth (Smits, 2013), modern scientific explanations start to take precedence at the start of the Meiji period. In the case of earthquakes and tsunamis, this is likely tied to the emergence of seismology and a new focus on the study of historical earthquakes in Japan (Smits, 2013; Good, 2016). A better understanding of the recurring nature of these hazards solidifies the need for the transmission of past events and messages to future generations. By the end of the 19th century, memory stones start to display more educational content and instructions of adequate behavior. This is especially well-documented in the case of earthquake and tsunami related memory stones.

Development in the understanding of hazards and more generally changes in society are reflected in these memory stones, making them an adaptive memory device. The latest example of such development, after the 2011 GEJET, is the inclusion of interactive elements, such as quick response codes on memory stones, linking to images and videos of the disaster (Weitzman, 2011).

\subsection{Considering how they act, memory stone sample in Shiga Prefecture}

In order to be communicable and gain a certain degree of temporal sustainability, memory needs to be externalized and materialized (Jordan, 2006). Material objects can thus act as a potential vector of memory. It is more specifically in the interaction between people and objects that memory becomes transmitted. The potential of memory stones as protective devices then needs to be studied from the standpoint of the interaction (or lack thereof) between people, especially locals and object.

In order to gain a more accurate understanding of the positioning of these disaster-related memory stones within communities, we conducted some preliminary fieldwork in Ötsu city, Shiga Prefecture (Spring, 2020) focusing on memory stones dedicated to water-related disasters. The main objective was to observe the stones in context and, from observation, gather information regarding their location, their physical characteristics and their accessibility and potential for interaction, in order to devise a system that would eventually 
help assess their workings and potential as memorialization devices. The sample consisted of seven stones that can be categorized into two disasters: three address the 1896 Great Flood, while the remaining four address other distinct water-related disasters (see Annexe). This limited sample still offered a chance to highlight potentially relevant characteristics that will serve as a base for future studies. They will of course need to be tested against other samples and need refining to reduce overlap, but this is beyond the scope of this field test.

As a first step towards understanding how these monuments function as mnemonic devices, it was first necessary to identify a series of basic criteria that, from the perspective of a material culture study, would allow building a more precise biography of these objects. Such a biography would in turn help to clarify what they can actually "do" in terms of disaster memory transmission, especially from a people-object interaction perspective.

The first aspects to consider are the physical characteristics directly observable on site (or in readily available public sources such as prefecture databases etc.). Observation of the sample allowed to identify such basic characteristics as type of stone (kinen-hi/kuy $\bar{o}$-hi), presence of disaster-related markers (i.e. water level in case of floods), content of the writing and presence or not of interactive elements (i.e. QR codes).

Once this basic typology had been established, the next step consisted in outlining a series of more in-depth criteria that can be characterized as interaction factors. We considered here are characteristics such as accessibility and visibility, presence or not of visible interaction (i.e. in the form of offerings), maintenance and also integration on site. This last item refers to how a memory stone is positioned in its physical environment and may include several sub-characteristics: stand-alone or integrated into a preexisting structure, accompanied or not by other monuments or information panels, etc. These interaction factors allow a better understanding of the positioning of these memory stones within local communities as memorialization devices and, as such, set the basis for a workable classificatory tool to be used in further studies related to disaster-related material culture.

\section{Discussion/conclusion: a cultural tool for disaster prevention}

In the past few decades, the realm of disaster studies has experienced a shift towards the exploration of more social aspects of disaster. Among these new focuses, considerations about local knowledge and practices, their transmission and role in the resilience of communities prone to specific hazards have given rise to significant research.

Under the umbrella term saigai bunka or "disaster culture", social scientists, notably folklorists and anthropologists, address the transmission, preservation and revival of traditional practices transmitted locally and the role they play in disaster-affected communities.

At the core of these relatively new preoccupations are the perceptions, knowledge and practices that local communities create and rely on in their adaptation and response to their environment. Directly related to adaptation, the issue of transmission is a crucial one for vulnerable communities.

Historical records, paintings and drawings, the literature, local lore and even rituals are well documented media that contribute to the transmission of past disasters (Hayashi, 2017; Webb, 2006). The disaster culture created by the combination of these various elements has the potential to either mitigate or exacerbate the impact of a hazard.

One aspect of disaster culture is the way communities memorialize disasters. Here memorialization is understood as any process that contributes to preserving and transmitting the memory of a disaster and its victims.

Through the process of memorialization, past events are conveyed through a variety of intangible forms, like rituals and oral narratives, as well as tangible forms, such as monuments and museums. A common intercultural example of the latter is the many war memorials designed to grieve and honor those lost, commemorate and remind future generations of a 
DPM 31,6

moment in history. In a similar vein, but perhaps lesser known, disasters have also been memorialized in tangible ways. Monuments have been erected in the aftermath of disasters throughout the world: the 1900 Galveston statue in the USA, multiple memorials and monuments related to the 2004 Indian Ocean tsunami are but a few examples.

Japan is no exception and, as discussed previously, has in fact developed through generations a deeply ingrained culture of disaster-related stone monuments, built in the aftermath of the most destructive, or the most locally significant, hazards. Present throughout the entire archipelago and some going back centuries, these disaster-related memory stones commemorate the variety of hazards systemic to Japan: from typhoons to landslides to earthquakes and tsunamis. The continued pervasiveness and development of memory stones, even in recent years, shows that they are, as Good (2016) suggests, "a familiar model seen to fulfill a useful social and cultural function".

The effectiveness and relevance of these stones has, however, been the object of debates among disaster scholars. Proponents of these stones will not fail to mention the seemingly miraculous case of Aneyoshi, while skeptics point to the fact that most of them have been forgotten by local communities.

Following the 2011 Great East Japan earthquake and tsunami, the Aneyoshi memory stone (Miyako town, Iwate prefecture) has often been cited as one example of the effectiveness and relevance of these stones. Erected in the aftermath of the 1933 Shōwa Sanriku Tsunami, it offers an unusually explicit warning: "Dwelling on higher ground [guarantees] peace for our descendants. Remember the sufferings of great tsunamis. Do not build homes below this point", followed by a description of the devastation: "Tsunamis reached this point in Meiji 29 and Shōwa 8, and destroyed the entire village. They left only 2, then 4 survivors. No matter how much time passes, be cautious". The village was subsequently rebuilt above the location of the stone and was not hit by the 2011 tsunami. Some locals attribute their survival to the wisdom of their ancestors to follow the warning on the stone (Fackler, 2011).

We should not, however, ignore the hundreds of other such tsunami stones that seemingly failed to safeguard locals in 2011. Hirakawa et al. (2016), in their study on the correlation between stone location and tsunami submersion in Iwate Prefecture, summarize the potentially ambivalent effectiveness of memory stones. On one hand, off the 176 stones in Iwate prefecture, $73.9 \%$ were not submerged by the 2011 tsunami, indicating that they could potentially be a good altitudinal marker for evacuation. On the other hand, some of the educational stones, despite being located in previously submerged zones, encourage people to evacuate "at this height", potentially putting people at risk with incorrect disaster narratives.

This critical view needs to be put in perspective. Disaster-related memory stones do not exist in a vacuum. They are but one element of a complex disaster culture and, as such, need to be thought and read in the context of concurring, sometimes conflicting, disaster mitigation tools and narratives.

Where infrastructural solutions often lead to loss of memory (Aspe and Jacqué, 2012; Metzer and Linton, 2016, 2017), local culture inscribes the memory of disaster in the locale and can contribute in passing it on. Stone monuments are but one tangible expression of this specific environment and the cultural expressions linked to it.

Actively rehabilitating and integrating them as cultural and local heritage, following Leblanc (2015) suggestion to "make the traces of disasters into heritage to maintain their memory and facilitate the management of future events" could be one way to put them to use on the DRR front. In this perspective, and even if this study does not claim to provide a definitive answer, several avenues can be suggested. The first is to consider it as a tool facilitating the process of mourning for the victims by associating it with regular on-site commemorations. Another avenue, not necessarily contradictory with the first, would also consist in using these monuments as symbols of the reconstruction of the city or the village, a choice often favored by the authorities (Boret and Shibayama, 2016). 
It is also possible to imagine an educational role for memory stones in the context of a range of activities, from school projects to cultural or historical walks. Like Liegeois (2014) pointed out, the participative aspect of such activities could also promote a more active sharing of memory between local residents, truly establishing the stones as a form of living heritage and bringing disaster memory into the present.

\section{References}

Aspe, C. and Jacqué, M. (2012), Environnement et société. Une analyse sociologique de la question environnementale, Quae, Paris.

Boret Penmellen, S. and Shibayama, A. (2016), "Archiving and memorializing disasters report of a UN international workshop", Journal of Disaster Research, Vol. 11 No. 3, pp. 437-442.

Boret Penmellen, S. and Shibayama, A. (2018), "The roles of monuments for the dead during the aftermath of the Great East Japan Earthquake", International Journal of Disaster Risk Reduction, Vol. 29, pp. 55-62.

Fackler, M. (2011), “Tsunami warnings, written in stone”, New York Times, 20 April, available at: www.nytimes.com/2011/04/21/world/asia/21stones.html (accessed 22 January 2020).

Garnier, E., Ciavola, P., Armaroli, C., Spencer, T. and Ferreira, O. (2017), "Historical analysis of storms events: case studies in France, England, Portugal and Italy", Coastal Engineering, Vol. 134, pp. 10-23.

Garnier, E. (2019), "Lessons learned from the past for a better resilience to contemporary risks", Disaster Prevention and Management, Vols 28-6, pp. 778-795.

Good, M. (2016), "Shaping Japan's disaster heritage”, in Matsuda, A. and Mengoni, L.E. (Eds), Reconsidering Cultural Heritage in East Asia, Ubiquity Press, London, pp. 139-161.

Hayashi, I. (2017), "Materializing Memories of disasters: individual experiences in conflict concerning disaster remains in the affected regions of the Great East Japan earthquake and tsunami", Bulletin of the National Museum of Ethnology, Vol. 41 No. 4, pp. 75-87.

Hirakawa, Y. (2016), "Tsunami-hi to tsunami shinsui-iki no ichi, taiō kankei to jinteki higai ni kansuru kōsatsu - Iwate ken engan no jirei (Considerations on the location and correspondence of the tsunami monument and the tsunami inundation area and human damage - case study on the coast of Iwate prefecture)", JSCE Proceedings B2 (Coastal Engineering), Vol. 72 No. 2, p. I-1621-1626.

Jordan, J.A. (2006), Structures of Memory: Understanding Urban Change in Berlin and beyond, Stanford University Press, Stanford.

Kawashima, S. (2016), "Tsunami-hi kara yomu saigai-kan - hitobito wa tsunami o dono yō ni toraete kita no ka (Disaster perspective from tsunami stones - how people apprehend tsunamis)", in Hashimoto, H. and Hayashi, I. (Eds), Saigai bunka no keishō to sōzōo (Creation and Transmission of Disaster Culture), Rinsen Shoten, Kyoto, pp. 44-65.

Kitahara, I. (2001), "Tōhoku sanken ni okeru tsunami-hi (Tsunami stones in Tōhoku three prefectures)", Tsunami kōgaku kenkyū hōkoku (Tsunami Engineering Research Report), Vol. 18, pp. 85-92.

Kitahara, I. (2004), "Exhibition on Documenting disaster: natural disasters in Japanese history 1703-2003”, Annals of Geophysics, Vol. 47, pp. 909-911.

Leblanc, A. (2015), "Résiliences, mémoires et pratiques", in Reghezza-Zit, M. and Rufat, S. (Eds), Résiliences. Société et territoires face à l'incertitude, aux risques et aux catastrophes, Iste éditions, London, pp. 175-186.

Liégeois, M. (2014), “Mémoire des catastrophes et culture du risque”, Pour, Vol. 223 No. 3, pp. 89-96.

Mendonça, D. and Amorin, I. (2018), "An historical perspective on common resilience: the case of the 1755 lisbon earthquake”, International Journal of Disaster Risk Reduction, Vol. 34, doi: 10.1016/j. ijdrr.2018.12.006. 
DPM

31,6

Metzger, A. and Linton, J. (2016), "Les barrages qui cachent l'eau: l'oubli des vulnérabilités aux inondations lors de l'aménagement de la Dordogne (1917-1935)", VertigO, Vol. 16 No. 3, doi: 10. 4000/vertigo.17985.

Metzger, A. and Linton, J. (2017), "Des inondations barrées ?”, Espace, populations, sociétés, No. 3, doi: 10.4000/eps.6631.

Murakami, H. (2008), Nankai Jishin O shiru - Tokushima-ken no Jishin, tsunami-hi (Understanding the Nankai Earthquake - Tokushima Prefecture's earthquake and tsunami stones), Research Centre for Management of Disaster and Environment, University of Tokushima, Tokushima.

Smits, G. (2013), Seismic Japan: the Long History and Continuing Legacy of the Ansei Edo Earthquake, University of Hawaii Press, Honolulu.

Suppasri, A., Shuto, N., Imamura, F., Shunichi, K., Mas, E. and Cevdet Yalciner, A. (2013), "Lessons learned from the 2011 Great East Japan tsunami: performance of tsunami countermeasures, coastal buildings, and tsunami evacuation in Japan”, Pure and Applied Geophysics, Vol. 170, pp. 993-1018.

Webb, G.R. (2006), "The popular culture of disaster: exploring a new dimension of disaster research", in Rodriguez, H., Quarantelli, E.L. and Dynes, R. (Eds), Handbook of Disaster Research, Springer, New York, pp. 430-440.

Weitzman, M. (2011), "First Japan tsunami monument has QR code video and advice. 23 December", available at: http://www.digitaljournal.com/article/316636 (accessed 22 January 2020).

\section{Further reading}

Kitahara, I. (2011), "Yomigaeraseyō tsunamihi no kyōkun (Let's revive the lessons from tsunami stones)", Kenchiku Zasshi (Architecture Journal), Vol. 126, pp. 34-35.

Kitahara, I. (2012), "Tsunami-hi wa ikitsudukete iru ka - Miyagi ken tsunami-hi chōsa hōkoku (Are tsunami stones still alive? Survey report of tsunami stones in Miyagi Prefecture)", Sagai fukkō kenkȳu (Research on Disaster Recovery), Vol. 4, pp. 25-42.

Smits, G. (2006), "Shaking up Japan: edo society and the 1855 catfish picture prints", Journal of Social History, Vol. 39 No. 4, pp. 1045-1078.

\section{Annexe}

The Annexe file is available online as supplementary material for this article.

\section{Corresponding author}

Emmanuel Garnier can be contacted at: emmanuel.garnier@univ-fcomte.fr

For instructions on how to order reprints of this article, please visit our website:

www.emeraldgrouppublishing.com/licensing/reprints.htm

Or contact us for further details: permissions@emeraldinsight.com 